\title{
Effect of drink temperature on antropyloroduodenal motility and gastric electrical activity in humans
}

\author{
W M Sun, R Penagini, G Hebbard, C Malbert, K L Jones, S Emery, J Dent, M Horowitz
}

\begin{abstract}
There is little information on the motor mechanisms underlying the effects of meal temperature on gastric emptying. The effects on antropyloric pressures and the surface electrogastrogram of ingesting drinks at $4^{\circ} \mathrm{C}, 37^{\circ} \mathrm{C}$, and $50^{\circ} \mathrm{C}(350 \mathrm{ml}$ normal saline and $50 \mathrm{ml}$ low calorie $(7 \mathrm{kj})$ orange cordial) given in randomised order were measured over 60 minutes in 12 normal volunteers (10 men and 2 women, aged 18-55 years). The warm and cold drinks suppressed antral pressure waves $(p<0.05)$, altered the organisation of antropyloric pressure waves $(\mathbf{p}<0.05)$, stimulated isolated pyloric pressure waves $(p<0.05)$, and increased electrogastrogram frequency $(p<0.05)$ when compared with the $37^{\circ} \mathrm{C}$ drink. These changes were greatest in the first 30 minutes after ingestion and greater $(p<0.05)$ with the $4^{\circ} \mathrm{C}$ drink. Temperature has major effects on postprandial antropyloroduodenal motility in normal subjects. Both cold and warm drinks stimulate a pattern of motility associated with retardation of transpyloric flow.
\end{abstract}

(Gut 1995; 37: 329-334)

Keywords: antropyloroduodenal motility, drink temperature, electrogastrogram, manometry.

The rate of gastric emptying is influenced by the chemical and physical characteristics of food. Food rich in nutrients or of high osmolality leaves the stomach slowly, primarily as a result of feedback on gastric motility from receptors in the small intestine. ${ }^{1-3}$ Meal temperature also influences gastric emptying. We have reported that a low nutrient liquid ingested either cold $\left(4^{\circ} \mathrm{C}\right)$ or warm $\left(50^{\circ} \mathrm{C}\right)$ empties from the stomach more slowly than a drink ingested at body temperature. ${ }^{4}$ The effects of meal temperature on gastric motility have been studied in humans ${ }^{5}$ and in monkeys. ${ }^{6}$ Temperature was not found to have any effect on antral motility but the measurement techniques and experimental protocols used in these studies had major limitations.

One of the possible mechanisms of action of meal temperature on emptying is via the gastric pacemaker which determines the timing and maximum rate of gastric contractions. ${ }^{7}$ The discharge of the gastric pacemaker can be recorded by surface electrogastrography (EGG). This non-invasive technique can detect gastric arrhythmias (tachygastria and bradygastria) in physiological and pathological situations. $^{8-11}$ There are no data on the effects of meal temperature on the EGG. It is also possible that meal temperature has an effect on the spatial organisation of gastric contractions, independent of any effect on the pacemaker frequency but the available studies are insufficient to give any indication on this possibility. Localised pyloric contractions probably have a major role in the regulation of nutrient liquid emptying by acting as a brake. ${ }^{112}$

Our aim in this study was to evaluate as definitively as possible the effects of the temperature of a low nutrient drink on antropyloroduodenal motility and the EGG in humans. To do this we used manometric methods, which enabled detailed analysis of the occurrence and spatial organisation of antral and pyloric pressure waves, concurrent with cutaneous recordings of the EGG.

\section{Methods}

\section{SUBJECTS}

Studies were carried out in 12 normal volunteers, ( 10 male, two female; aged $18-55$ years). None had a previous history of gastrointestinal disease or was taking medication. Smoking was prohibited from the evening before the study. The protocol was approved by the Human Ethics Committee of the Royal Adelaide Hospital in 1992 and each subject gave written informed consent.

\section{PROTOCOL}

The study began at approximately $10 \mathrm{am}$, after an overnight fast. A manometric assembly incorporating a sleeve sensor was passed into the stomach via an anaesthetised nostril. The sleeve was positioned across the pylorus by monitoring the antral and duodenal transmucosal potential difference (TMPD). ${ }^{12} 13$ Two adhesive electrodes were attached to the skin between the umbilicus and xiphoid to record gastric electrical activity (electrogastrogram - EGG). ${ }^{14} \mathrm{~A}$ third adhesive electrode served as a reference (Fig 1). The experiments were performed with the subject in a semirecumbent position and the upper body at $45^{\circ}$ from the bed. Each $400 \mathrm{ml}$ drink consisted of $350 \mathrm{ml}$ saline and $50 \mathrm{ml}$ low calorie $(7 \mathrm{kj})$ orange cordial (Cottee's, NSW, Australia), $290 \mathrm{mOsml} / \mathrm{l}, \mathrm{pH} 3.5$, and was given three times at $4^{\circ} \mathrm{C}, 37^{\circ} \mathrm{C}$, or $50^{\circ} \mathrm{C}$ during phase I of the migrating motor complex. The order of the temperatures was randomised and each drink 


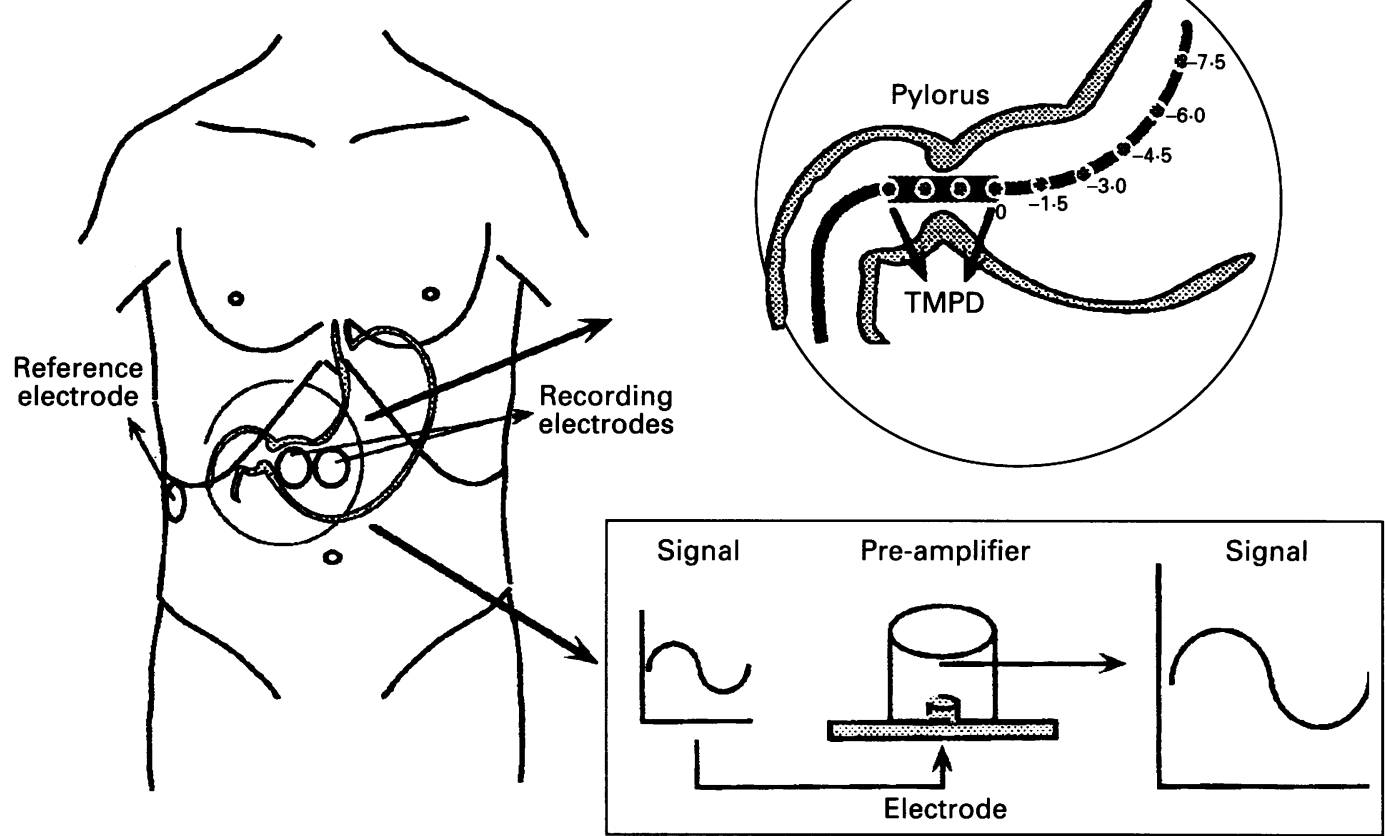

Figure 1: Diagram showing the manometric assembly and the method of recording gastric electrical activity. Pressure sideholes 6 and 9 (counting from the proximal end of the manometric assembly) were used to measure transmucosal potential difference (TMPD) in the distal antrum and proximal duodenum respectively to ensure correct assembly positioning. $A 4.5 \mathrm{~cm}$ sleeve sensor was located between the 6th and 9th sideholes, so that pressures generated by the very narrow zone of localised pyloric contraction were frequently recorded by the manometric sideholes along the sleeve.

was consumed within three minutes. These drinks and temperatures were essentially identical to those used in our previous study. ${ }^{4}$ Antropyloroduodenal pressures and EGG were recorded for 60 minutes following each of the drinks and drinks were separated by at a minimum time interval of 90 minutes. Time zero was considered to be the time of completion of drink ingestion.

\section{MEASUREMENTS}

\section{Antropyloric pressures}

The 10 lumen manometric assembly was similar to that used in previous studies (Fig 1).1214 The nine manometric sideholes were arranged at $1.5 \mathrm{~cm}$ intervals spanning the antrum and pylorus. A $4.5 \mathrm{~cm}$ sleeve sensor monitored pyloric contractions and was located between the sixth and ninth sideholes, counting from the proximal end of the manometric assembly. In order to define sleeve position, TMPD was monitored using the manometric sideholes at either end of the sleeve. ${ }^{15}$ All manometric channels were perfused with degassed distilled water at a rate of $0.3 \mathrm{ml} / \mathrm{min}$, except the TMPD channels, which were perfused with degassed normal saline at the same rate. ${ }^{13}$ Manometric signals were amplified by a 16 channel polygraph (Synectics, Sweden). The signals were subsequently digitised at $10 \mathrm{~Hz}$ using an A-D card (NB-MIO16, National Instruments, Texas, USA) board, and then processed and stored in an Apple Macintosh Quadra 700 computer using proprietary software (MAD 16, Synectics/Royal Adelaide Hospital/C $H$ Malbert) developed using the Lab View package (National Instruments).

\section{Electrogastrography}

To ensure optimal electrical contact of the surface electrodes, the abdominal skin was cleaned with ethanol and lightly abraded. The electrical signals were preamplified with a purpose designed preamplifier (Synectics, Sweden) (Fig 1). A Butterworth band-pass filter (attenuation $24 \mathrm{~dB}$ per octave) was used. The low and high cut off frequencies were 0.02 $\mathrm{Hz}$ and $0.28 \mathrm{~Hz}(-3 \mathrm{~dB})$ respectively. EGG signals were sampled at $10 \mathrm{~Hz}$ and also stored on the Apple Macintosh Quadra 700 computer.

\section{DATA ANALYSIS}

Recordings were only analysed when the sleeve sensor was positioned correctly according to the following criteria: when the antral TMPD was equal to or more negative than $-20 \mathrm{mV}$, the duodenal TMPD was equal to or more positive than $-15 \mathrm{mV}$, and the difference between the two readings was at least $15 \mathrm{mV} .{ }^{15}$ The first minute of recording after completion of the drink was excluded from data analysis (see below).

\section{Terminology and definition of pressure waves}

Phasic pressure changes which had an amplitude $\geqslant 10 \mathrm{~mm} \mathrm{Hg}$, and lasted for between 5-25 seconds were considered to be lumen occlusive pressure waves. ${ }^{12}$ An antropyloric pressure wave (APW) recorded by two or more sideholes was defined as a sequence when it occurred in at least one antral sidehole as well as the pylorus, and had onset times in adjacent channels within -5 to +10 seconds of each. ${ }^{16}$ Isolated pyloric pressure waves (IPPWs) were 
Antropyloric pressures and gastric electrical activity (EGG) after drinks at $4^{\circ} \mathrm{C}, 37^{\circ} \mathrm{C}$, and $50^{\circ} \mathrm{C}$.

\begin{tabular}{llll}
\hline & \multicolumn{4}{l}{ Temperature of drinks } \\
\cline { 2 - 4 } & $4^{\circ} \mathrm{C}$ & $37^{\circ} \mathrm{C}$ & $50^{\circ} \mathrm{C}$ \\
\hline First APW after drinking (min) & $22(5)^{\star}$ & $13(4)$ & $19(5)$ \\
No of APWs/60 min & $21(5)^{\star} \dagger$ & $33(5)$ & $29(7)^{\star}$ \\
No of IPPWs/60 min & $30(9)^{\star}$ & $19(7)$ & $26(7)^{\star}$ \\
Change in basal pyloric pressure & & & \\
$\quad$ (mmHg) 10 min after the drink & $+0 \cdot 1(0 \cdot 1)$ & $+0.8(0.5)$ & $+0.9(0.05)$ \\
Mean EGG frequency (Hz) & $0.061(0.0)^{\star} \dagger$ & $0.047(0.01)$ & $0.053(0.01)^{\star}$ \\
\hline
\end{tabular}

${ }^{\star} \mathrm{p}<0.05$ cf $37^{\circ} \mathrm{C} ; \mathrm{tp}<0.05$ cf $50^{\circ} \mathrm{C} ; \neq$ compared with 2 minutes before the drink. $\mathrm{APW}=$ antropyloric pressure wave; IPPW = isolated pyloric pressure wave.

defined as pressure waves that were detected by the sleeve sensor and by no more than one sidehole within the sleeve length, provided there was also absence of a pressure wave within \pm 5 seconds of any magnitude that was ascribable to either gastric or duodenal contraction. ${ }^{17}$ Basal pyloric pressure was defined as the difference between the basal pressure recorded by the sleeve sensor and the distal antral (antral TMPD) pressure after editing of phasic pressure, ${ }^{12} 151819$ and was scored

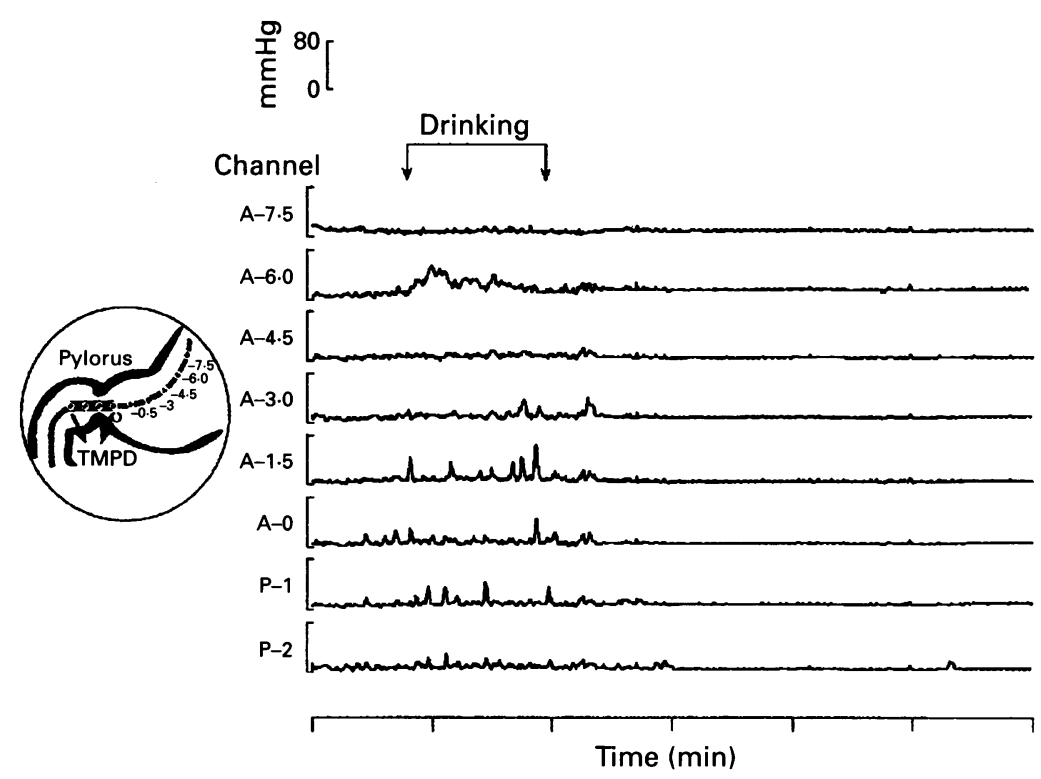

Figure 2: Representative recording of antropyloric pressure waves during and directly after drink ingestion $\left(37^{\circ} \mathrm{C}\right)$ showing the inhibition of pressure waves.

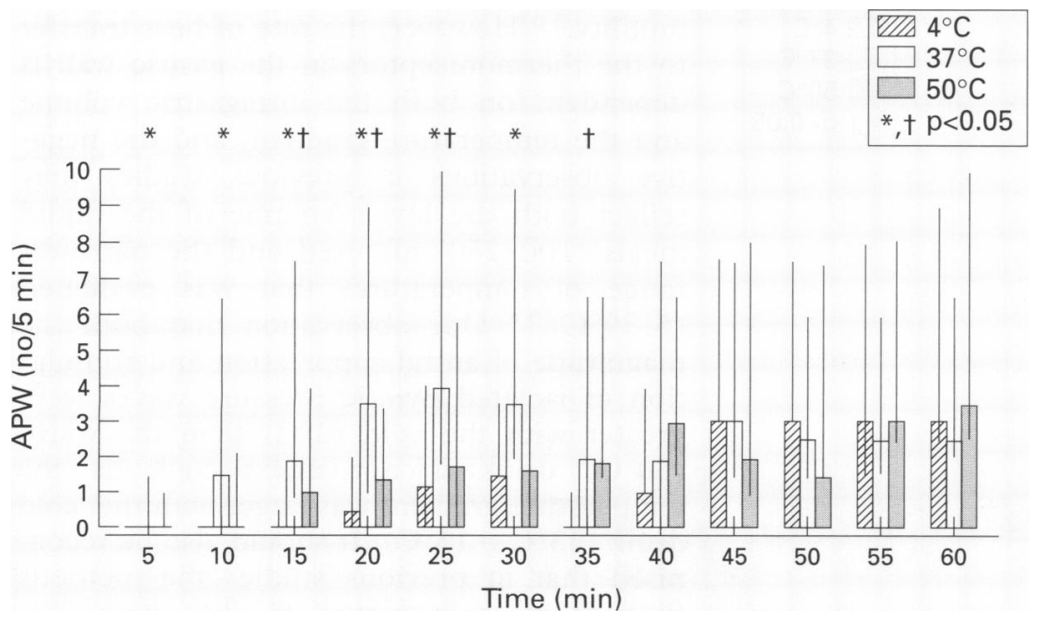

Figure 3: Group data for the number of antropyloric pressure waves (APW) per 5 minutes according to drink temperature. There were more $A P W$ after the $37^{\circ} \mathrm{C}$ drink than after the other two drinks for the first 30 minutes $\left({ }^{\star} p<0.05\right)$ and more $A P W$ after the $50^{\circ} \mathrm{C}$ drink than the $4^{\circ} \mathrm{C}$ drink $(\uparrow p<0.05)$. between 2-3 minutes before and 5-6, 10-11, and 30-31 minutes after each drink.

\section{Electrogastrography (EGG)}

EGG signals were processed by fast Fourier transformation (FFT) in order to obtain individual spectra. ${ }^{20} \mathrm{~A}$ Hanning window for the signal was used, as this method allows optimal definition of amplitude. ${ }^{21}$ The running spectral analysis was updated every minute from the preceding four minutes with an overlap period of three minutes. The mean frequency of the EGG was derived from the highest frequency of each spectrum.

\section{STATISTICAL ANALYSIS}

The number of pressure waves for either five or 10 minute recording periods are expressed as median values and interquartile range. Other data are presented as mean (SD). Statistical significance was examined using the quasilikelihood method, ${ }^{22}$ a $p$ value $<0.05$ being considered significant in all analyses.

\section{Results}

The experiments were well tolerated by all subjects. There were no significant differences in the time taken for subjects to consume the different drinks $\left(1.8(1.4)\right.$ minutes for $4^{\circ} \mathrm{C} ; 1.7$ $(1 \cdot 1)$ minutes for $37^{\circ} \mathrm{C}$, and $1.9(1.2)$ minutes for $\left.50^{\circ} \mathrm{C}\right)$. The sleeve sensor was positioned correctly $>90 \%$ of the time. Satisfactory EGG signals were obtained for $88 \%$ of the time during cold drink, $86 \%$ of the time during warm drink, and $91 \%$ of the time after a drink at body temperature. After ingestion of the drinks there was no change in the quality of the signal.

During consumption of each drink, there were some pressure waves in the distal antrum and pylorus (Fig 2), but directly after completion of the drink there was a period of motor quiescence (Fig 2). The first APW occurred earlier after the quiescent period $(p<0.05)$ following the $37^{\circ} \mathrm{C}$ drink than after the $4^{\circ} \mathrm{C}$ drink (Table). The effects of temperature on the number and organisation of APWs, IPPWs, and EGG frequency are summarised in the Table. There were fewer APWs $(p<0.05)$ after the $4^{\circ} \mathrm{C}$ drink than after both the $37^{\circ} \mathrm{C}$ and the $50^{\circ} \mathrm{C}$ drinks. For all three drinks, the number of APWs increased gradually during the first 30 minutes and did not change after that time $(p<0.05)$ (Fig 3). For the first 30 minutes following the $37^{\circ} \mathrm{C}$ drink the number of APWs in each five minute period was greater $(\mathrm{p}<0.05)$ when compared to both the warm and cold drinks $(\mathrm{p}<0.05)$ (Fig 3$)$.

After each of the drinks most APWs were confined to the distal antrum (Fig 4). For both the cold and the warm drinks, there were fewer APWs in the proximal three antral sideholes in the first 30 minutes than in the second 30 minutes (Fig 4), whereas there was no difference with the $37^{\circ} \mathrm{C}$ drink. In the first 30 minutes, the number of APWs in both the proximal and the distal antral sideholes was greater $(p<0.05)$ after the $37^{\circ} \mathrm{C}$ drink than after 


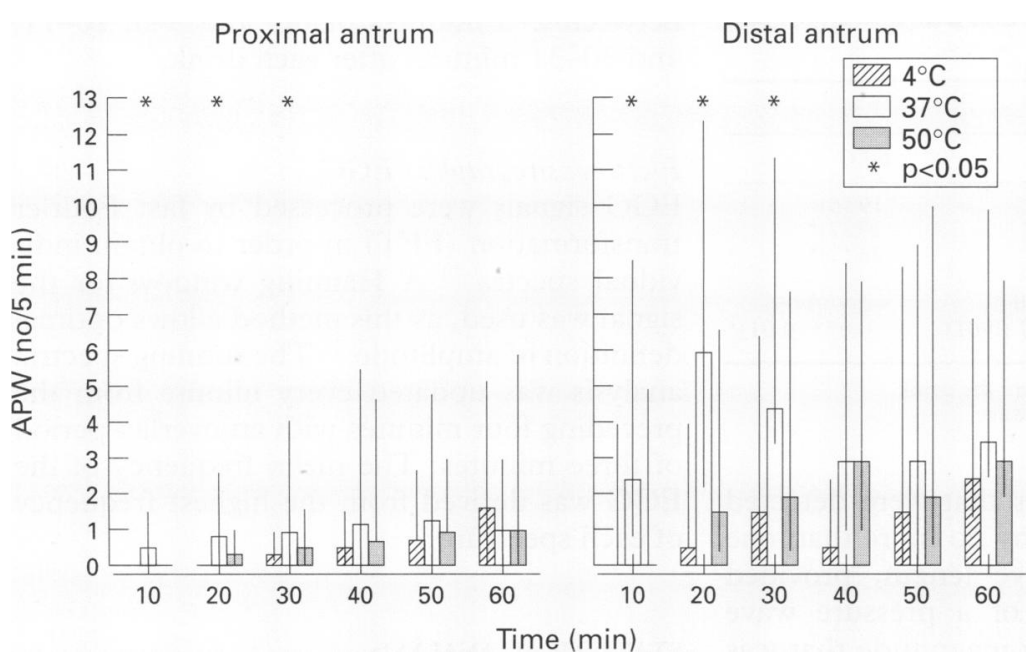

Figure 4: Number of antropyloric pressure waves (APW) originating in the proximal and distal antrum after the drinks. The effect of drink temperature on the number of APW was greatest for the distal antrum. The number of $A P W$ was greater after the $37^{\circ} \mathrm{C}$ drink than the other drinks for the first 30 minutes $\left({ }^{\star} p<0.05\right)$. Proximal and distal antrum were defined as regions between sideholes that were located at $7 \cdot 5-4 \cdot 5 \mathrm{~cm}$ and $3 \mathrm{~cm}$-antral transmucosal potential difference channel respectively.

both the warm and cold drinks (Fig 4). This effect of temperature on the more proximal antrum was not apparent in the distal antrum, as with all three drinks there were no significant differences in the number of APWs in the distal three sideholes between the first and the second 30 minutes (Fig 4; p>0.05).

There were fewer IPPWs $(p<0.05)$ in the first 30 minutes with the $37^{\circ} \mathrm{C}$ drink than with both the cold and warm drinks (Table) and there were more IPPWs $(\mathrm{p}<0.05)$ after the $4^{\circ} \mathrm{C}$ drink than after both the $50^{\circ} \mathrm{C}$ and $37^{\circ} \mathrm{C}$ drinks (Fig 5). There was a gradual increase in the number of IPPWs for up to about 25 minutes after each drink (Fig 5, p<0.05). The rate of increase of IPPWs in the first 30 minutes was less $(\mathrm{p}<0.05)$ after the $37^{\circ} \mathrm{C}$ drink than after both the $4^{\circ} \mathrm{C}$ and the $50^{\circ} \mathrm{C}$ drinks. Beyond 25 minutes, the number of IPPWs decreased $(p<0.05)$ for all three drinks. Drink temperature had no effect on basal pyloric pressure (Table).

After the $37^{\circ} \mathrm{C}$ drink, the mean EGG frequency was similar to the predrink values

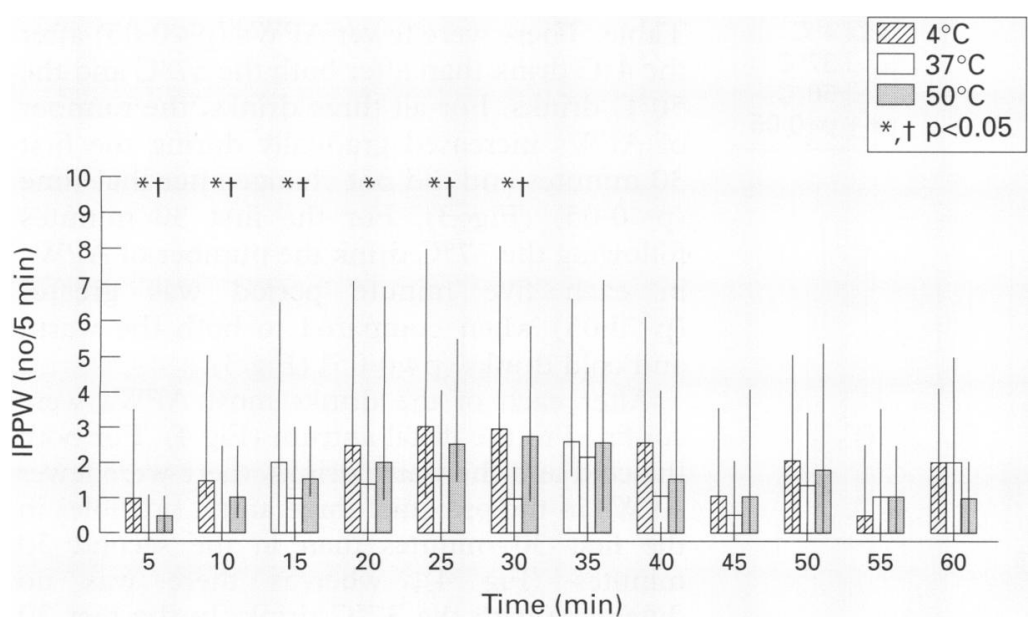

Figure 5: Effect of drink temperature on the number of isolated pyloric pressure waves (IPPW) over time. The increase over the first 30 minutes was less following the $37^{\circ} \mathrm{C}$ drink compared to the other two drinks $\left({ }^{\star} p<0 \cdot 05\right)$. There were less after the $50^{\circ} \mathrm{C}$ drink than the $4^{\circ} \mathrm{C}$ drink $(\dagger p<0.05)$.
$(0.049(0.018) \mathrm{Hz} v 0 \cdot 047(0 \cdot 01) \mathrm{Hz})$. Both the $4^{\circ} \mathrm{C}$ and the $50^{\circ} \mathrm{C}$ drinks were associated with a higher $(p<0.05)$ mean EGG frequency than the $37^{\circ} \mathrm{C}$ drink (Table). This increase was due to periods of $6-10 \mathrm{cpm}(0 \cdot 1-0 \cdot 17 \mathrm{~Hz})$ EGG oscillation $(\mathrm{p}<0.05)$. There was no evidence of $3 \mathrm{cpm}(0.05 \mathrm{~Hz})$ activity during $6-10 \mathrm{cpm}$ activity (Fig 6). The 6-10 cpm periods occurred most frequently within the first 30 minutes after the cold and warm drinks (Fig 7).

\section{Discussion}

We have reported previously that changes in meal temperature influence gastric emptying. ${ }^{4}$ The temperatures tested in our study represent the greatest range of normal drink temperature. These, and the content of the drink, were virtually identical to those examined in our previous study, ${ }^{4}$ so that comparable effects on gastric emptying would be anticipated. ${ }^{4}$ The mechanics of gastric emptying are complex, being dependent on the interaction of mechanical effects of the variable patterns of contraction of the proximal stomach, antrum, pylorus, and proximal small intestine. ${ }^{23-25} \mathrm{It}$ does not seem that there is normally a single dominant mechanism which controls gastric emptying. ${ }^{26}$ The spatial/temporal organisation of gastric pressure waves may be a more important determinant of their mechanical consequences than their absolute number. ${ }^{27}$ The present study, which is the first detailed investigation of the effects of meal temperature on gastric motility, shows that the cold and warm drinks cause suppression of antral pressure waves, alterations in the organisation of antral pressure waves and stimulation of pressure waves localised to the pylorus. These changes are likely to contribute to the retardation of gastric emptying produced by warm and cold drinks. Because of the significant impact of drink temperature on gastric emptying and antropyloric motility, this variable needs to be controlled for in studies of gastric motility and emptying.

At first glance our findings seem to be at variance with two previous studies, one in monkeys and the other in humans, which found no effect of temperature on antral motility. ${ }^{56}$ However, the rate of heat transfer to the thermoreceptors in the gastric wall is dependent on both the intragastric volume and the temperature gradient, and the negative observations in previous studies may reflect both the lower volume of the liquid meals $(100-250 \mathrm{ml})$ used and the narrower range of temperatures that was evaluated $\left(5-39^{\circ} \mathrm{C}\right) .{ }^{56}$ Our observation that both the magnitude of antral suppression and stimulation of isolated pyloric pressure waves were greater with the cold $\left(4^{\circ} \mathrm{C}\right)$ than the warm $\left(50^{\circ} \mathrm{C}\right)$ drink is not unexpected, as the temperature gradient was larger with the cold drink $\left(33^{\circ} \mathrm{C} v 13^{\circ} \mathrm{C}\right)$. It should also be recognised that in previous studies the methods used to measure gastric motility were suboptimal. ${ }^{56}$ For example, in the human studies, pressures were recorded at only one recording site in the antrum ${ }^{5}$ and in the animal study, 


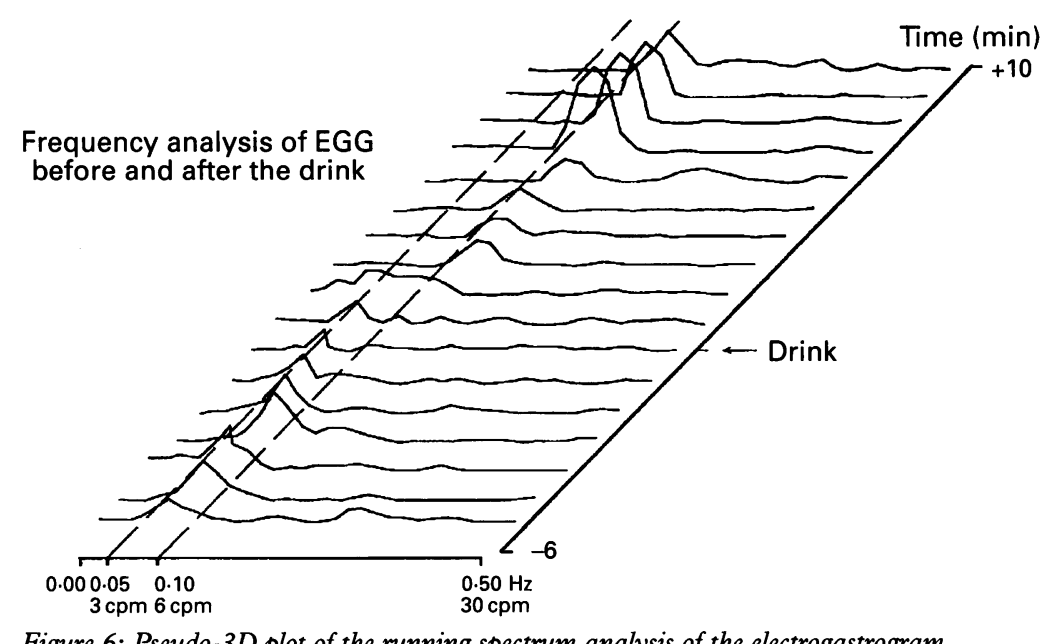

Figure 6: Pseudo-3D plot of the running spectrum analysis of the electrogastrogram (EGG), before, during, and after a $4^{\circ} \mathrm{C}$ drink. After the drink 6-10 activity is apparent.

antral motility was evaluated with only one extraluminal strain gauge. ${ }^{6}$ These methods could not give information about pyloric contractions or the spatial patterning of antral contractions, variables that could be assessed fully in our study because of the use of multiple, closely spaced, manometric side holes. Unlike the present study, previous studies ${ }^{5}$ did not control for the effect of the phase of the interdigestive motor complex on gastric emptying and gastric motility. This is likely to have been a significant confounder, given the larger variations of antral motility that occur during the interdigestive cycle, which persist after ingestion of non-nutrient liquids in volumes in excess of those tested. ${ }^{27} 28$ Less direct studies by $\mathrm{El}$ and $\mathrm{Mei}^{29}$ in cats, have found evidence for temperature effects in that both cold $\left(10-12^{\circ} \mathrm{C}\right)$ and warm $\left(46-49^{\circ} \mathrm{C}\right)$ solutions infused into the duodenum inhibited antral spike activity, a finding which is compatible with our observation of reduced antral pressure waves.

Cold and warm drinks changed the patterns of antral pressure waves in that antral motility was totally suppressed for about 10 minutes. We have previously reported that the effects of temperature on gastric emptying are greatest

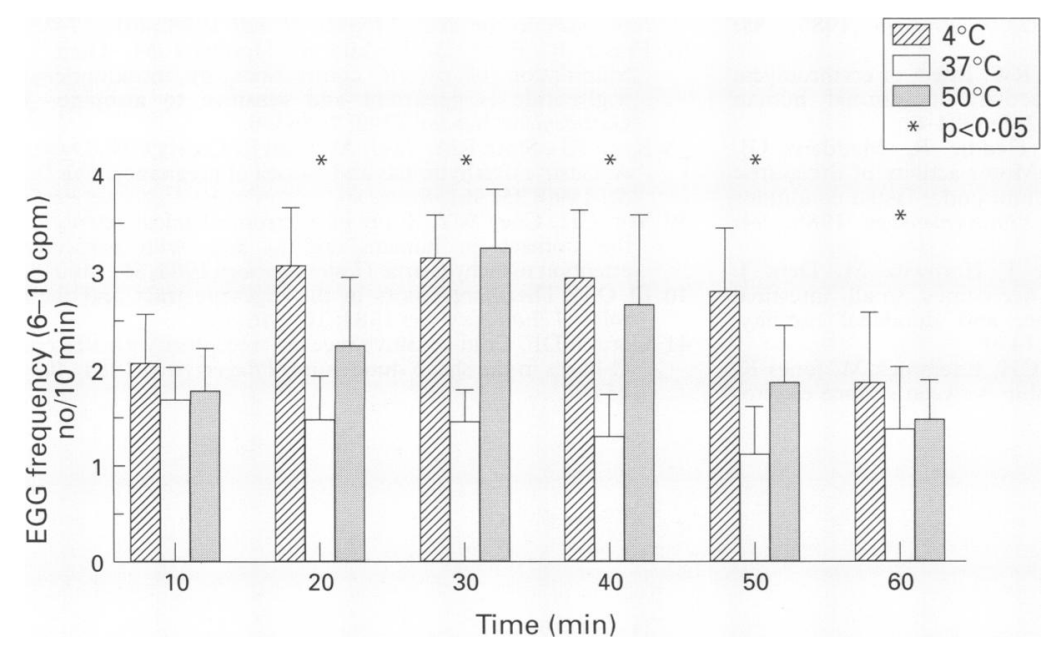

Figure 7: The number of minutes that the 6-10 cpm $(0 \cdot 1-0 \cdot 17 \mathrm{~Hz})$ component of electrogastrogram (EGG) was present in each 10 minute period. The amount of $6-10 \mathrm{cpm}$ activity was less after the $37^{\circ} \mathrm{C}$ drink than the other two drinks $\left({ }^{\star} p<0 \cdot 05\right)$. during this time. ${ }^{4}$ While it is possible that the reduced number of pressure waves in the antrum could reflect larger antral volumes as a result of slow gastric emptying, this seems unlikely as the effects of temperature were evident soon after ingestion of the drinks, when differences in antral area are likely to be minimal, ${ }^{30}$ and were similar in the proximal and distal antrum.

Our data are the first to evaluate the effects of drink temperature on pyloric motility and suggest that the pylorus also plays a role in the temperature induced slowing of gastric emptying. Both cold and warm drinks stimulated IPPWs, a contraction pattern that has been shown to prevent transpyloric flow. ${ }^{31}$ The association of IPPW stimulation with slowing of gastric outflow is strong, since previous studies have shown that the retardant effects in gastric emptying of small intestinal nutrient infusion, ${ }^{1819}$ cold stress, ${ }^{32} 33$ and induced hyperglycaemia ${ }^{34} 35$ are also associated with stimulation of IPPWs. These previous studies also found that basal pyloric pressure was increased concurrent with IPPWs. We cannot determine from the current experiment why pyloric tone was not stimulated by the cold and warm drinks, but have observed a similar dissociation between the tonic and phasic localised pyloric motor responses to duodenal distension in humans. ${ }^{16}$ There are other indications that pyloric tone and IPPWs are controlled separately, or at least have differing stimulation thresholds. ${ }^{36} 37$ Our data do not exclude an effect of temperature on proximal gastric tone and proximal small intestinal motility, which might also contribute to effects on gastric emptying. To our knowledge no studies have addressed this possibility.

The changes in EGG frequency observed after the cold and warm drinks are of uncertain significance. The $6-10 \mathrm{cpm}$ frequency of EGG oscillation produced by the cold and warm drinks has previously been defined as tachygastria. It is seen with glucagon induced antral motor inhibition ${ }^{10}$ and is associated with nausea ${ }^{38}$ and delayed gastric emptying. ${ }^{8} 939 \mathrm{It}$ is possible that bursts of tachygastria lead to antral motor inhibition following the warm and cold drinks and thereby contribute to slowing of gastric emptying. The prevalence of tachygastria after the $37^{\circ} \mathrm{C}$ drink was higher than expected. While we have no definitive explanation to account for this observation, it is unlikely to represent a harmonic frequency of $3 \mathrm{cpm}$ as the observed frequency was never precisely twice the fundamental frequency.

Our study was not designed to identify the mechanisms that mediate the effects of temperature on gastric motility but other studies suggest several possibilities. Three types of thermoreceptors which are silent at normal body temperature ${ }^{29} 40$ have been demonstrated in the cat stomach and duodenum. Cold receptors start to respond at temperatures below $36^{\circ} \mathrm{C}$, peaking at $10-12^{\circ} \mathrm{C}$; warm receptors respond most intensely at $46-49^{\circ} \mathrm{C}$; and mixed thermoreceptors respond to both warming and cooling of the mucosal surface. ${ }^{29}$ Cottrell has described cold sensitive 
mechanoreceptors in the sheep duodenum when recording from afferent $C$ fibres, suggesting that thermoreceptors may respond to multiple stimuli. ${ }^{41}$ The time effects observed in our present study give some indication of possible mechanisms, as these mirror the changes in intragastric temperature that we have observed after ingestion of cold or warm drinks. ${ }^{4}$ After ingestion of $400 \mathrm{ml}$ drinks at $4{ }^{\circ} \mathrm{C}$ or $50^{\circ} \mathrm{C}$, intragastric temperature returns to within $1^{\circ} \mathrm{C}$ of body temperature after $20-30$ minutes. ${ }^{4}$ While the observation that differences in antropyloric pressures were still apparent at 15 minutes can be interpreted as indicating that minor changes in intragastric (proximal small intestinal) temperature may affect antropyloric motility, it is perhaps more likely that these effects are prolonged after the initial stimulation of these receptors when the temperature differences (from body temperature) are greatest.

The project was supported by the National Health and Medical Research Council of Australia. Dr W M Sun is the recipient of Research Council of Australia. Dr W M Sun is the recipient of
a Florey Fellowship provided by the Royal Adelaide Hospital. a Florey Fellowship provided by the Royal Adelaide Hospital. ing the amplifiers for pressure and EGG recordings and Ms K ing the amplifiers for pressu

This paper was presented during Digestive Diseases Week of the American Gastroenterological Association and was published in abstract from Gastroenterology 1994; 106: A574.

1 Heddle R, Collins PJ, Dent J, Horowitz M, Read NW, Chatterton B, et al. Motor mechanisms associated with slowing of the gastric emptying of a solid meal by an intraduodenal lipid infusion. $\mathcal{F}$ Gastroenterol Hepatol 1989; 4: 437-47.

Spiller RC. The ileal brake-inhibition of jejunal motility after ileal fat perfusion in man. Gut $1984 ; 25$ : 365-74

3 Welch IM, Cunningham KM, Read NW. Regulation of gastric emptying by ileal nutrients in humans. Gastric emptying by ileal nutronterology 1988;94: 401-4.

4 Sun WM, Houghton LA, Read NW, Grundy DG, Johnson AG. Effect of meal temperature on gastric emptying of liquids in man. Gut 1988; 29: 302-5.

5 Kagawa Busby KS, Heitkemper MM, Hansen BC, Hanson $\mathrm{RL}$, Vanderburg VV. Effects of diet temperature on tolerance of enteral feedings. Nurs Res 1980; 29: 276-80

6 Williams KR, Walike BC. Effect of the temperature of tube feeding on gastric motility in monkeys. Nurs Res 1975; 24 : 4-9.

7 Szurszewski JH. Electrical basis for gastrointestinal motility. In: Johnson LR, ed. Physiology of the gastrointestinal tract. New York: Raven Press, 1987: 383-422.

8 Koch KL, Stern RM, Stewart WR, Vasey MW. Gastric emptying and gastric myoelectrical activity in patients with diabetic gastroparesis: effect of long-term domperiwith diabetic gastroparesis: effect of long-term domperi-

9 Telander RL, Morgan KG, Kreulen DL, Schmalz PF, Kelly $\mathrm{KA}$, Szurszewski JH. Human gastric atony with tachygastria and gastric retention. Gastroenterology 1978; 75: 497-501

10 Abell TL, Malagelada JR. Glucagon-evoked gastric dysrhythmias in humans shown by an improved electrogastrographic technique. Gastroenterology 1985; 88: $1932-40$

11 Chen J, Yeaton P, McCallum RW. Effect of erythromycin on gastric myoelectrical activity in normal human subjects. Am $\mathcal{F}$ Physiol 1992; 263: G24-8.

12 Houghton LA, Read NW, Heddle R, Maddern GJ, Downton J, Toouli J, et al. Motor activity of the gastric Downton J, Toouli J, et al. Motor activity of the gastric and after a liquid meal. Gastroenterology 1988; 94: and after

13 Fraser R, Shearer T, Fuller J, Horowitz $M$, Dent J. Intravenous erythromycin overcomes small intestinal feedback on antral, pyloric, and duodenal motility. Gastroenterology 1992; 103: 114-9.

14 Sun WM, Smout A, Malbert CH, Edelbroek M, Jones K, Horowitz $M$, et al. Relationship between surface electro- gastrography and antropyloric pressure. Am $\mathcal{f}$ Physiol 1995; 268: G424-30.

15 Heddle R, Dent J, Toouli J, Read NW. Topography and measurement of pyloric pressure waves and tone in humans. Am F Physiol 1988; 255: G490-7.

16 Edelbroek M, Horowitz M, Dent J, Sun WM, Malbert C, Smout A, et al. Effects of duodenal distension on fasting and postprandial antropyloroduodenal motility in humans. Gastroenterology 1994; 106: 583-92.

17 Heddle R, Fone D, Dent J, Horowitz M. Stimulation of pyloric motility by intraduodenal dextrose in normal subpyloric motility by intraduodenal

18 Edelbroek $M$, Horowitz $M$, Fraser $R$, et al. Adaptive changes in the pyloric motor response to intraduodenal dextrose in normal subjects. Gastroenterology 1992; 103: 1754-61.

19 Heddle R, Dent J, Read NW, et al. Antropyloroduodenal motor responses to intraduodenal lipid infusion in healthy volunteers. Am F Physiol 1988; 254: G671-9.

20 Van der Schee EJ, Smout AJPM, Grashius JL. Application of running spectrum analysis to electrogastrographic signals recorded from dogs and man. In: Wienbeck M, ed. Motility of the digestive tract. New York: Raven Press, 1982: 241-50.

21 National Instruments Corporation. $\mathrm{Ch} 6$ Analysis examples. In: LabView 2. New York, 1990: 14-5.

22 Zeger SL, Liang K-Y. Longitudinal data analysis for discrete and continuous outcomes. Biometrics 1986; 42: 121-30. 23 Houghton LA, Read NW, Heddle R, et al. Relationship of the motor activity of the antrum, pylorus, and duodenum to gastric emptying of a solid-liquid mixed meal. Gastroenterology 1988; 94: 1285-91.

24 Lin HC, Doty JE, Reedy TJ, Meyer JH. Inhibition of gastric emptying by sodium oleate depends on length of intestine exposed to nutrient. Am f Physiol 1990; 256: G1031-6.

25 Heddle R, Miedema BW, Kelly KA. Integration of canine proximal gastric, antral, pyloric, and proximal duodenal motility during fasting and after a liquid meal Dig Dis Sci 1993; 38: 856-69.

26 Horowitz M, Dent J, Fraser R, Sun WM, Hebbard G. Role and integration of mechanisms controlling gastric emptying. Dig Dis Sci 1994; 39: 7-13S.

27 Sun WM, Malbert C, Jones K, Horowitz M, Dent J. Variation in spatial patterns of antropyloric pressure waves - a determinant of gastric mechanics? Gastroenterology 1993; 104: A589.

28 Oberle RL, Chen T, Lloyd C, Barnett JL, Owyang G, Meyer J, Amidon GL. The influence of the interdigestive migrating myoelectric complex on the gastric emptying of liquids. Gastroenterology 1990; 99: 1175-82.

$29 \mathrm{El} \mathrm{OT}, \mathrm{Mei}$ N. Vagal thermoreceptors in the gastro-intestinal area. Their role in the regulation of the digestive motility. Exp Brain Res 1979; 34: 419-34.

30 Bolondi L, Bortolotti M, Santi V, Calletti T, Gaiani S, Labò G. Measurement of gastric emptying time by real-time G. Measurement of gastric emptying time by rea-

31 Tougas G, Anvari M, Dent J, Somers S, Richards D, Stevenson GW. Relationship of pyloric motility to pyloric opening and closure in healthy subjects. Gut 1992; 33: 466-71.

32 Fone DR, Horowitz M, Maddox A, Akkermans LM, Read NW, Dent J. Gastroduodenal motility during the delayed gastric emptying induced by cold stress. Gastroenterology 1990; 89: 1155-61.

33 Thompson DG, Richelson E, Malagelada JR. Perturbation of upper gastrointestinal function by cold stress. Gut 1983; 24: 277-83.

34 MacGregor IL, Gueller R, Watts HD, Meyer JH. The effect of acute hyperglycaemia on gastric emptying in man. Gastroenterology 1976; 70: 190-6.

35 Fraser R, Horowitz M, Dent J. Hyperglycaemia stimulates pyloric motility in normal subjects. Gut 1991; 32: 475-8

36 Allescher HD, Daniel EE, Dent J, Fox JE, Kostolanska F. Extrinsic and intrinsic neural control of pyloric sphincter pressure in the dog. 7 Physiol (Lond) 1988; 401: 17-38.

37 Fraser R, Fone D, Heddle R, Horowitz M, Dent J. Stimulation of pyloric contractions by intraduodenal triglyceride is persistent and sensitive to atropine. $\mathcal{f}$ Gastroenterol Hepatol 1992; 7: 563-8.

38 Koch KL, Stern RM, Vasey M, Botti JJ, Creasy GW, Dwyer A. Gastric dysrhythmias and nausea of pregnancy. Dig Dis Sci 1990; 35: 961-8.

39 You CH, Chey WY. Study of electromechanical activity of the stomach in humans and in dogs with particular attention to tachygastria. Gastroenterology 1984; 86: 1460-8.

$40 \mathrm{El} \mathrm{OT}$. Thermoreceptors in the digestive tract and their roles. F Auto Nerv Sys 1984; 10: 246-54.

41 Cottrell DF. Cold-sensitive mechanoreceptors with afferent C-fibres in the sheep duodenum. Pflugers Arch 1984; 402: 454-7. 